\title{
Properties Evaluation of Cotton Ring and Compact Spun Yarns after Scouring and Bleaching Process
}

Abdul SB* and Sandip J

Center for Textile functions, Mukesh Patel School of Technology, Management \& Engineering, NMIMS University, Dhule, India

\begin{abstract}
Yarn prepared from two technologies i.e. Ring frame and compact spinning system analyzed on Uster Tensorapid, Uster Evenness Tester. It was observed that yarn prepared with compact spinning system gives less variation in end products. Study also reveals that there was significant difference between tensile properties of yarn which was produced from compact spinning and ring spinning. Yarn produced from two technologies pretreated with scouring and bleaching process and structural changes occurred in yarn were analyzed on Uster Tensorapid, Uster Evenness Tester. In the present investigation it was observed that yarn produces from both spinning technique shows, strength reduced and elongation improved in compact spun yarn and count C.V. also found reduced for both systems after scouring and bleaching process. It was noticed that, yarn produced from compact spinning gives less yarn hairiness because of reduction in spinning triangle and protruding fibers were goes into yarn body which gives very good impact on subsequent processes.
\end{abstract}

Keywords: Scouring; Bleaching; Yarn strength; Count c.v.\%; Thick place; Thin place; Neps; Imperfections

\section{Introduction}

Compact spinning process has become firmly established in the market in recent years. This technology offer superior quality and better raw material utilization compact yarn displays considerably improved yarn parameters, especially in terms of hairiness however conventional ring spinning has always being and still is a world class yarn manufacturing system. Convectional ring spinning has greatest flexibility compare to all new spinning system in its scope of countless application. The newly developed compact spinning system which is the improvement existing conventional ring spinning system holds a great potential to reduce hairiness significantly due to special techniques used in it.

Chemical and Mechanical finishing process change properties of fiber assemblies according to its intensity cotton fiber contain approximately $90 \%$ cellulose and various non-cellulose substances such as waxes, fats, pectin, proteins and coloring matter. Cotton contains impurities, which are present in the fiber as they occur or which have been added or which have been added to it at some stage of processing prior to the preparation. The added impurities include spinning oils, gums, fatty compound, oil stains while the naturally occurring impurities include nitrogenous and mineral matter, oils, waxes, pectin's, and coloring matter and pigment.

An adequate preparation is necessary either to remove or to decolorize the impurities present in cotton so that they will not interfere in the subsequent process the purpose of bleaching includes the removal of the various natural, added and acquired impurities from the grey cloth and efficiently as possible, with minimum or no damage of the fiber, and leaving the yarn in a perfectly white state. The damage to the yarn reflects in drop in tensile strength of the yarn, cause by lowering of the degree of polymerization of cellulose chains due to molecular chain break down. Bleaching being a preparatory process should be carried out properly, as any faults in bleaching would affect all the subsequent process. The bleaching process aims at achieving the following general's goals. A high and uniform absorbency of the yarn/fabric and high and uniform degree of permanent whiteness has least damage to the yarn/ fabric. Bleaching is the removal of unwanted color from the textile fibers and typically involves the use of one of the bleaching agent is Hydrogen peroxide in different concentration.

\section{Application methods}

Using Exhaustion method at temperature $110^{\circ} \mathrm{C}$ for $20 \mathrm{~min}$.

\section{RFD normal process:}

Chemicals used:

1. Mix A

- Perlavin epo- $0.45 \%$

- Peristal ep- $0.15 \%$

- Caustic soda- $2.00 \%$

2. Mix B

- Hydrogen peroxide $\left(\mathrm{H}_{2} \mathrm{O}_{2}\right)-1.50 \%$

3. Mix C

- Invatex ac- $0.100 \%$

- Acetic acid- $0.700 \%$

- Perizym red- $0.180 \%$

M:L:R:-1: 6 to $1: 7$

Preparation A: is added in stock tank contain Hot water $\left[70^{\circ} \mathrm{C}\right]$ mixed well and transferred to the main KIER where the Grey cheese

*Corresponding author: Abdul SB, Center for Textile functions, Mukesh Pate School of Technology, Management \& Engineering, NMIMS University, Dhule, India, E-mail: abdulsalaambagwan@gmail.com

Received September 02, 2013; Accepted September 16, 2013; Published September 22, 2013

Citation: Abdul SB, Sandip J (2013) Properties Evaluation of Cotton Ring and Compact Spun Yarns after Scouring and Bleaching Process. J Textile Sci Eng 3: 139. doi:10.4172/2165-8064.1000139

Copyright: @ 2013 Abdul SB, et al. This is an open-access article distributed under the terms of the Creative Commons Attribution License, which permits unrestricted use, distribution, and reproduction in any medium, provided the original author and source are credited. 
Citation: Abdul SB, Sandip J (2013) Properties Evaluation of Cotton Ring and Compact Spun Yarns after Scouring and Bleaching Process. J Textile Sci Eng 3: 139. doi:10.4172/2165-8064.1000139

Page 2 of 3

carrier is loaded. Run at $70^{\circ} \mathrm{C}$ for 4 Minute $\left(\mathrm{H}_{2} \mathrm{O}_{2}\right.$ is readily available in Addition tank) [1].

Preparation B: $\mathrm{H}_{2} \mathrm{O}_{2}$ is injected to the main KIER. Raise the temperature to $100^{\circ} \mathrm{C}$ Run for 30 minute and "HT" draining the Bath. [Hot water $\left(80^{\circ} \mathrm{C}\right)$ is readily available in stock tank]. Then Hot water is transferred to main KIER and Run for 10 Minutes [2].

Preparation C: is readily available in stock tank containing warm water $\left(50^{\circ} \mathrm{C}\right)$ and drain the bath. Then the Preparation " $\mathrm{C}$ " is transferred to the main KIER and run for 15 minute and drains the bath.

Check point:

- Absorbency

- Whiteness [Visual/Instrumental]

$\cdot \mathrm{pH}$

- Residual $\mathrm{H}_{2} \mathrm{O}_{2}$

- Substrate Hardness [In case of Grey lot change].

The above checks are recorded on the Drug Sheet.

\section{The bleaching process includes three main steps}

Saturating the fabric with the bleaching agent and other necessary chemicals

- Raising the temperature to the recommended level for the particular textile and maintaining the temperature for a set period of time.

- Thoroughly washing and drying the Yarn/fabric.

The main object of this study is to understand of the effect following factor on tensile properties of yarn, which are listed below.

- The effect of spinning technology on properties of yarn

- The property evaluation of ring and compact yarn

- The effect of bleaching process on properties ring and compact yarn [3].

\section{Experimental}

The experimental design consists of yarn produced with two spinning systems. In this study, $40 \mathrm{Ne}$ ring \&compact cotton yarn were spun with carded under similar technological condition on ring spinning machine. After yarn spinning, grey yarn produced with two technologies tested for its physical properties, grey yarn is converted to soft package of specific density and then taken for one bath scouring and bleaching treatment [4]. Eventually, bleached yarns were tested for their frictional, tensile and other physical properties and testing result of grey and bleached yarn properties given in Table 1.

\section{Results and Discussion}

\section{The effect of spinning technology on properties of yarn}

The yarn produced in both compact and conventional ring spinning. A standard spinning preparation was used to produce conventional and compact yarn under comparable technological condition on KTTM ring frame machine. Rotor craft is as an device used in compact spinning, fitted on front top roller of the ring frame, in order to produce good quality of yarn. After spinning yarn with both techniques, the physical properties of each yarn were measured and result of conventional yarn,

\begin{tabular}{|c|c|c|c|c|}
\hline Normal Count & $\begin{array}{c}\text { 40 C Ring yarn } \\
\text { Before Bleach }\end{array}$ & $\begin{array}{c}\text { 40 CH Ring } \\
\text { yarn After } \\
\text { Bleach }\end{array}$ & $\begin{array}{c}\text { 40 CWR } \\
\text { Compact } \\
\text { Before Bleach }\end{array}$ & $\begin{array}{c}\text { 40 CWR } \\
\text { Compact } \\
\text { After Bleach }\end{array}$ \\
\hline Actual Count & 39.76 & 39.41 & 40.27 & 40.30 \\
\hline Count CV \% & 1.08 & 1.02 & 1.11 & 0.74 \\
\hline Strength (Lbs) & 52.70 & 48.12 & 77.50 & 68.22 \\
\hline C.S.P & 2095 & 1956 & 3121 & 3112 \\
\hline U\% & 10.34 & 9.82 & 9.99 & 9.44 \\
\hline Thin & 0.0 & 7.5 & 0.0 & 2.5 \\
\hline Thick & 35.0 & 30.25 & 25.0 & 17.5 \\
\hline Neps & 60.0 & 45.23 & 40.0 & 27.5 \\
\hline $\begin{array}{c}\text { Total } \\
\text { Imperfection }\end{array}$ & 95.0 & 82.98 & 65.0 & 47.5 \\
\hline Hairiness & 6.18 & 7.18 & 3.97 & 4.08 \\
\hline RKM & 16.29 & 16.71 & 18.20 & 22.19 \\
\hline RKM CV\% & 9.00 & 8.38 & 7.98 & 7.32 \\
\hline Elongation & 4.28 & 5.71 & 5.13 & 5.51 \\
\hline Elongation & 9.40 & 8.27 & 11.03 & 5.84 \\
\hline C.V \% & & & & \\
\hline
\end{tabular}

Table 1: Grey yarn testing result before and After RFD Process.

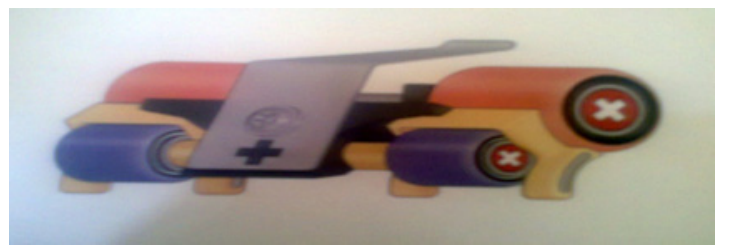

Figure 1: Rotor craft device in compact spinning.

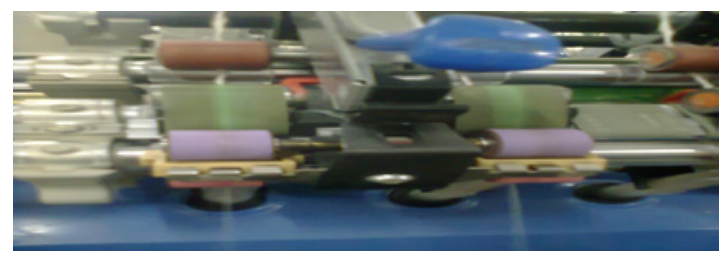

Figure 2: Rotor craft device fitted on ring frame in compact spinning

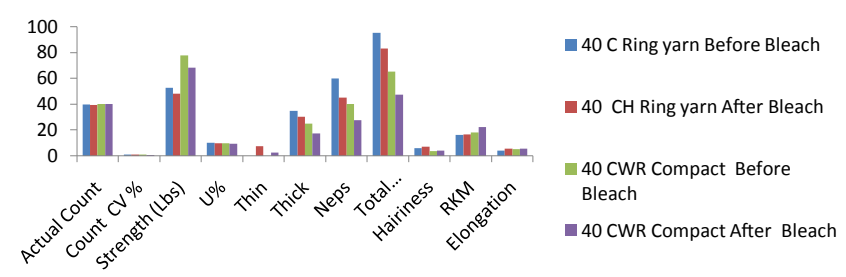

Figure 3: Comparative evaluations between ring and compact yarn, before and after bleaching process.

compact yarn were compared to each other. Yarn prepared from two technologies analyzed on Uster Tensorapid, Uster Evenness Tester [5].

It was observed that from Table 1 and Figures 1-3 yarn prepared with compact spinning gives less variation in end products i.e. because of reducing spinning triangle by placing rotor craft device in compact spun yarn. It was also statistically proved that, there was significant difference between tensile properties of yarn which was produced from compact spinning and conventional spinning technique. 
The property evaluation of grey ring and grey compact spun yarn and effect of bleaching process on properties of ring and compact yarn

Effect of bleaching process on ring and compact yarn count: It has been found that from Figure 1 there is no significant difference between count of grey and bleach ring yarn but compact yarn shift towards finer yarn, the result may be because of suction present on compact spinning system as each fiber which goes in the yarn assembly, all the fiber in finely packed from and their by reduce weight per yarn assembly hence compact yarn count may become slightly finer than ring yarn [6].

Effect of bleaching on yarn strength: From Figure 3 and Table 1 it has been found that the strength values for grey yarn is each category are higher than that of bleached yarn because, before bleaching treatment, the frictional values of grey yarn are higher than that of bleached yarn because of wax material, impurities which was present in grey yarn, In the yarn after bleaching removal of wax, led is decrease cohesion between the fiber and eventually decrease in strength, but compare to ring yarn compact spun yarn recorded more strength.

Effect of bleaching on yarn imperfections: From Figure 3 and Table 1 , the unevenness and imperfection values for bleached yarn almost in every case are found less than that of grey yarn. This is because during bleaching, various changes take place in the yarn geometry, also natural impurities present in the fiber as well as foreign particle such as kitties, dust and lint's having length less than $1 \mathrm{~cm}$ are removed out. Along with this, after bleaching yarn shrink and fiber orientation take place towards most stable structure which might have resulted into reduction in $\mathrm{U} \%$ after bleaching.

Effect of bleaching process on ring and compact yarn elongation: Figure 3 and Table 1 shows that there was significant difference was found between elongation (\%) values of grey and bleach ring and compact yarn. The elongation (\%) values for bleached yarn in each category are found higher than that of grey yarn. This result may be due to shrinkage in yarn after bleaching process which causes fiber the reorientation in bleach yarn at relax stage and resulted in to higher elongation [7].

Also there was significant difference between elongation values of grey and bleached ring and compact yarn where as similarly significant difference between elongation values of grey and bleach ring and compact yarn. In both this cases elongation values of compact yarn were higher than that of ring yarn this result may be because of uniform twist distribution in compact yarn structure, increase in packing density, regular mass distribution and excellent fiber lay [8].

Effect of bleaching process on ring and compact yarn hairiness: From Figure 3 and Table 1 it was found that there was difference between hairiness values of grey and bleached ring and compact yarn. Hairiness values (number of protruding fiber having fiber length more than $3 \mathrm{~mm}$ ) increase after yarn bleaching process compared to hairiness of grey yarn. This result is due to the package rewinding process which takes place after bleaching treatment and thereby increase the no. of protruding fiber out from surface of the yarn body. After yarn bleaching fiber lay at yarn surface gets disturbed due to yarn swelling and there by gives increase in yarn hairiness. Also significant difference between the values of ring and compact grey and bleach yarn was found where as similarly significant difference was found between values of ring and compact grey and bleach yarn. In this both cases values of compact yarn are significantly less than that of ring yarn because, the drafted assembly of the fiber is condensed before twist is imparted and this compacting zone helps to compact protruding fiber by metered air flow this suction binds the protruding mass of the fiber parallel to the yarn axis rigidly which leads to reduce hairiness substantially.

\section{Conclusion}

The present investigation reveals that after yarn bleaching treatment is liable to disturb surface properties of the yarn such as decrease in strength value of yarn. Similarly, yarn bleaching treatment results in increase in yarn extension and yarn hairiness and reduction in imperfection values. Study also reveals that compact yarn can be more profitably as it displays significantly better yarn properties than a conventional ring spun yarn after bleaching treatment.

\section{References}

1. Sarvanan D, Ramchandran $T$ (2010) Bleaching of cotton fabrics using hydrogen peroxide produced by glucose oxidase Ind J Fibre Text Res 35: 281-283.

2. Jones BM, Langlois GW, Sakaji RH (1985) Effect of ozonation and UV irradiation on biorefractory organic solutes in oil shale retort water. Environ Prog 4: 252-258.

3. Changhai Xu, David H, Ahmed El-S, Peter HM, Mary A et al. (2011) Review of Bleach Activators for Environmentally efficient bleaching of textiles. J Fiber Bioeng Infor 4: 209-219.

4. Broadbent AD (2001) Basic Principles of Textile Coloration. Society of Dyers and Colourists, Cambridge, UK.

5. Cotton Preparation Manual, Sarex, Maharashtra, India

6. Rastar A, Hoseinpour A (2011) Simultaneous Dyeing and Bleaching of Cotton Materials. World App Sci J 14: 1186-1189.

7. Shenai VA(1991) Technology of Bleaching and Mercerizing. Sevak Publications New Dehli, India.

8. John S (2002) Colourant \& Auxiliaries. Woodhead Publishing Limited 2: 602 607. 